\title{
Quantitative proteomics for identifying biomarkers for tuberculous meningitis
}

\author{
Ghantasala S Sameer Kumar ${ }^{1,2}$, Abhilash K Venugopal ${ }^{1,2,3,4}$, Anita Mahadevan ${ }^{5}$, Santosh Renuse ${ }^{1,3,4,6}$, H C Harsha', \\ Nandini A Sahasrabuddhe ${ }^{1,7}$, Harsh Pawar ${ }^{1,8}$, Rakesh Sharma ${ }^{9}$, Praveen Kumar ${ }^{1}$, Sudha Rajagopalan ${ }^{10}$, \\ Keith Waddell ${ }^{11}$, Yarappa L Ramachandra ${ }^{2}$, Parthasarathy Satishchandra ${ }^{12}$, Raghothama Chaerkady ${ }^{1,2,3,4}$, \\ T S Keshava Prasad ${ }^{1,6,7,13}$, K Shankar ${ }^{5^{*}}$ and Akhilesh Pandey ${ }^{1,3,4,14,15^{*}}$
}

\begin{abstract}
Introduction: Tuberculous meningitis is a frequent extrapulmonary disease caused by Mycobacterium tuberculosis and is associated with high mortality rates and severe neurological sequelae. In an earlier study employing DNA microarrays, we had identified genes that were differentially expressed at the transcript level in human brain tissue from cases of tuberculous meningitis. In the current study, we used a quantitative proteomics approach to discover protein biomarkers for tuberculous meningitis.

Methods: To compare brain tissues from confirmed cased of tuberculous meningitis with uninfected brain tissue, we carried out quantitative protein expression profiling using ITRAQ labeling and LC-MS/MS analysis of SCX fractionated peptides on Agilent's accurate mass QTOF mass spectrometer.

Results and conclusions: Through this approach, we identified both known and novel differentially regulated molecules. Those described previously included signal-regulatory protein alpha (SIRPA) and protein disulfide isomerase family A, member 6 (PDIA6), which have been shown to be overexpressed at the mRNA level in tuberculous meningitis. The novel overexpressed proteins identified in our study included amphiphysin (AMPH) and neurofascin (NFASC) while ferritin light chain (FTL) was found to be downregulated in TBM. We validated amphiphysin, neurofascin and ferritin light chain using immunohistochemistry which confirmed their differential expression in tuberculous meningitis. Overall, our data provides insights into the host response in tuberculous meningitis at the molecular level in addition to providing candidate diagnostic biomarkers for tuberculous meningitis.
\end{abstract}

Keywords: Relative quantitation, Cerebrospinal fluid, Histopathology, Early diagnosis, Tuberculosis

\section{Introduction}

Tuberculosis (TB) is a common and sometimes fatal transmissible disease, especially in developing countries. Approximately thirty percent of the global population is exposed to the acid-fast bacilli causing TB. Of those who are infected with tuberculosis, $\sim 10 \%$ percent develop a clinical manifestation of the disease during their lifetime. From a global perspective, approximately twenty percent of $\mathrm{TB}$ infected population live in India. The World

\footnotetext{
* Correspondence: shankarsk2004@gmail.com; pandey@jhmi.edu

${ }^{5}$ Department of Neuropathology, National Institute of Mental Health and

Neurosciences, Bangalore 560029, India

'Institute of Bioinformatics, International Technology Park, Bangalore 560066, India

Full list of author information is available at the end of the article
}

Health Organization (WHO) has estimated that one million children develop TB annually worldwide which accounts for about $11 \%$ of all TB cases [1]. Tuberculous bacilli most commonly infect lungs. Mycobacterium tuberculosis (MTB) may also spread to extrapulmonary sites including the meninges, lymph nodes, genitourinary tract, skeletal system and skin [2]. Tuberculous meningitis (TBM) is the infection of meninges caused by MTB, with a mortality rate of $\sim 30 \%$. Further, those who survive TBM are usually left with severe neurological defects [3-5]. There is an increased risk of TBM in HIV-infected patients as compared to non-HIV infected cases although the clinical manifestations of the disease do not differ between the two groups [6,7].

\section{Biomed Central}


Culturing mycobacteria and subsequent microbiological examination is considered a gold standard for the diagnosis of TBM. However, this method is time consuming and insensitive, with a positive outcome achieved only in $25-70 \%$ of clinically diagnosed cases [8]. Although PCR assays can be an alternative rapid approach for diagnosis, they cannot differentiate between latent or active forms of the disease. Although nucleic acid amplification test (NAAT) has a high specificity when tested in body fluids, it lacks adequate sensitivity in cases of meningitis and pleuritis [9].

Amongst the existing molecular markers, Adenosine deaminase isoenzyme-2 (ADA2) has a sensitivity of $100 \%$ and a specificity of $86.4 \%$ for the detection of TBM in cerebrospinal fluid (CSF) [10]. Adenosine deaminase (ADA) activity in the CSF of TBM patients has been suggested to be useful for early differential diagnosis of TBM [11]. The ADA activity of CSF and plasma have been evaluated as a diagnostic aid in TBM [12] and ADA activity in CSF was considered to be a simple, useful and rapid diagnostic test for early recognition of TBM in children [13]. However, overexpression of ADA was also often overexpressed in other forms of meningitis including infections with pyogenic bacteria [14]. In the CSF of TBM patients, the presence of $65 \mathrm{kDa}$ heat shock protein antigen might be a marker for early diagnosis of the disease [15]. High levels of CSF lactate and lactate dehydrogenase levels have also been suggested for diagnosing TBM [16].

Early diagnosis of TBM is considered a key to effective treatment and prognosis. Approximately $90 \%$ of the patients are diagnosed in stage II or III [17]. Overall, the diagnosis of TBM still remains a major challenge due to inadequate current diagnostic methods and poor sensitivity and/or specificity of existing markers. Although corticosteroids are used extensively to reduce mortality and neurological disability, it may not be the only solution to reduce the mortality and morbidity [18]. In TBM, a number of pathological changes including meningeal adhesion, infarction, tuberculoma and hydrocephalus may occur leading to neurological sequelae [4]. These sequelae are known to correlate with the stage of meningitis at admission. Patients treated at an early stage have a five times higher chance of recovery than those with advanced disease stages [19]. Therefore, patient's clinical condition at admission and delay in starting the treatment are important factors for determining their survival [20]. These findings emphasize the need to focus on identifying candidate molecular markers which can be developed as diagnostic tools in the management of TBM.

Mass spectrometry-based quantitative proteomics has emerged as a powerful approach for identifying and studying disease biomarkers and has become one of the essential tools in biomarker discovery [21,22]. Advances in quantitative mass spectrometry have led to identification and quantitation of biomarkers which serve as indicators of disease progression, prognosis, drug safety and help to elucidate the mechanism of drug treatment [23]. There are various labeling approaches that one can employ to carry out quantitative proteomic measurements. In vitro labeling methods include Isobaric Tags for Relative and Absolute Quantitation (iTRAQ), Isotope-Coded Affinity Tags (ICAT), ${ }^{18} \mathrm{O}$ labeling and in vivo methods include Stable Isotope Labeling by Amino acids in Cell culture (SILAC) and ${ }^{15}$ Nlabeling [24,25]. iTRAQ labeling is an effective method for studying differential protein expression levels in tissue samples. It has been extensively used for biomarker discovery in various disease contexts [26-34].

In this study, we used an iTRAQ-based quantitative proteomic approach to identify differentially expressed proteins from brain tissues of tuberculous meningitis cases as compared to controls. We identified several proteins which are differentially expressed in TBM. These proteins include both novel and previously reported candidate protein markers. We validated some of these candidate biomarkers using immunohistochemical labeling.

\section{Materials and methods}

\section{Sample collection}

The study was approved by scientific ethics committee of National Institute of Mental Health and Neuro Sciences (NIMHANS), Bangalore, India. Samples from frontal cortex with overlying meninges from cases of tuberculous meningitis $(n=6)$ and similar, but uninfected, control brain tissues $(n=6)$ from victims of road traffic accidents were collected at the time of autopsy. The autopsy was conducted within $8-16 \mathrm{~h}$ postmortem with the body kept at $4^{\circ} \mathrm{C}$ after death. The samples were obtained from the Human Brain Tissue Repository, Department of Neuropathology, NIMHANS, Bangalore. Sample details including the selection criteria are provided in Additional file 1: Table S1.

\section{Sample preparation and iTRAQ labeling}

Brain tissue samples were lysed in $0.5 \%$ SDS, sonicated, homogenized and centrifuged at 13,000 rpm for $10 \mathrm{~min}$ at $4^{\circ} \mathrm{C}$. Supernatant was collected and protein quantitation was carried out by Lowry's assay (Bio-Rad Hercules, CA; USA). For each condition, $160 \mu \mathrm{g}$ of protein sample was utilized for the experiment. Each sample was treated with $4 \mu \mathrm{L}$ of reducing agent (tris (2-carboxyethyl) phosphine (TCEP)) at $60^{\circ} \mathrm{C}$ for $1 \mathrm{~h}$ and alkylated with $2 \mu \mathrm{L}$ of cysteine blocking reagent, methyl methanethiosulfonate (MMTS) for $10 \mathrm{~min}$ at room temperature. After alkylation, the samples were subjected to trypsin digestion (Sequencing Grade Modified Trypsin, Promega Cat\#: 
V511A) using 1:20 (w/w) at $37^{\circ} \mathrm{C}$ for $16 \mathrm{~h}$. Peptide samples from each condition was split in equal halves $(80 \mu \mathrm{g}$ each) and labeled with iTRAQ 4-plex reagents (catalog \# 4352135, Applied Biosystems, Foster City, CA, USA) as per manufacturer's protocol. We used technical replicates for control and TBM samples. Peptides from control samples were labeled with iTRAQ reagents yielding reporter ions 114 and 115 while peptides from TBM were labeled with 116 and 117 . The samples were pooled following iTRAQ labeling.

\section{Strong cation exchange chromatography (SCX)}

Pooled iTRAQ labeled peptides were fractionated by strong cation exchange chromatography on PolySULFOETHYL A column (200 x $2.1 \mathrm{~mm} ; 5 \mu \mathrm{m} ; 200 \AA$ PolyLC, Columbia, MD) using Agilent's 1200 series HPLC system. The peptides were reconstituted in SCX solvent A (10 mM potassium phosphate, $25 \%$ acetonitrile, $\mathrm{pH} 2.8$ ) and loaded on SCX column isocratically using $100 \%$ solvent A for $20 \mathrm{~min}$ at a flow rate of $200 \mathrm{ul}$ per minute. Peptides were eluted using a 30 min gradient from $8 \%$ to $35 \%$ solvent B (350 $\mathrm{mM} \mathrm{KCl}$ in solvent A). Fractions were collected every minute using a fraction collector. The fractions were vacuum dried and stored at $-80^{\circ} \mathrm{C}$ until LC-MS/MS analysis.

\section{LC-MS/MS analysis}

The samples were analyzed on HPLC chip-cube interfaced with Accurate Mass 6520 quadrupole time of flight mass (QTOF) spectrometer (Agilent Technologies, Santa Clara, CA). The HPLC-Chip contains a $40 \mathrm{nl}$ enrichment column and $43 \mathrm{~mm} \times 75$ um analytical column. These columns were made up of a reversed-phase material Zorbax $300 S B-C_{18}$, with a particle size of $5 \mu \mathrm{m}$. The samples were loaded onto the enrichment column using Agilent's 1200 series capillary liquid chromatography pump at a flow rate of $3 \mu \mathrm{l} / \mathrm{min}$ using $97 \%$ solvent $\mathrm{A}$ and $3 \%$ solvent B. An injection flush volume of $4 \mu \mathrm{l}$ was applied during enrichment step. The peptides were eluted at a flow rate of $400 \mathrm{nl} / \mathrm{min}$ using a gradient of solvent A ( $0.1 \%$ formic acid) and solvent B ( $0.1 \%$ formic acid in $90 \%$ acetonitrile). The gradient was started from $3 \%$ to $18 \%$ of solvent B over 8 min, subsequently changed to $22 \% \mathrm{~B}$ in the next $7 \mathrm{~min}$ and finally changed to $45 \%$ of solvent B for $25 \mathrm{~min}$. MassHunter workstation data acquisition software (Version B.01.03) was used for data dependent acquisition. MS spectra were acquired for 1 second from m/z 350-1800 followed by three MS/MS spectra in next second comprising the duty cycle of 2.1 second including an interscan delay of 0.1 second. Precursor ions were preferred based on charge state in the order of $2+, 3+$ and $>3+$. The capillary and fragmentor voltage of $1950 \mathrm{~V}$ and $175 \mathrm{~V}$ respectively was applied with a medium isolation width of $4 \mathrm{~m} / \mathrm{z}$ and a collision energy slope of $3 \mathrm{~V}$ plus at offset of $2 \mathrm{~V}$.

\section{Data analysis}

The mass spectrometry raw data was processed to peak list format by using MassHunter Qualitative Analysis software (Agilent Technologies, Version B.03.3). These processed peak list files were then searched against Human RefSeq Protein Database (Release 40) containing 31,811 protein sequences through Proteome Discoverer platform (Thermo Scientific, Version 1.2). The workflow includes spectrum files, spectrum selector, Mascot and Sequest search nodes followed by peptide validator for false discovery analysis whereas a reporter ion quantifier was used for quantitation. Search parameters included trypsin as the enzyme with one missed cleavage allowed, oxidation of methionine, deamidation at aspargine and glutamine were set as a variable modification whereas methyl-thio at cysteine and iTRAQ label at N-terminus of the peptide and lysine were set as a fixed modification. The reporter ion window tolerance was set at $100 \mathrm{ppm}$. The identified peptides were filtered using $1 \%$ false discovery rate derived using decoy database search strategy and top ranked hit based on peptide score, XCorr and IonScore for Sequest and Mascot respectively. The search results from both Masoct and Sequest were merged and unique peptide(s) identified for each protein were used to calculate relative protein quantitation in Proteome Discoverer workflow. The average ratio was used for relative protein quantification for proteins with multiple peptide matches. Bioinformatic analysis was carried out to categorize proteins based on biological processes, cellular component and molecular function classification using annotations in Human Protein Reference Database (HPRD, http://hprd. org) [35], which is in compliance with gene ontology (GO) standards.

\section{Immunohistochemical labeling}

Formalin fixed and paraffin embedded autopsy tissues were collected and cut into $4 \mu \mathrm{m}$ thick sections on glass slides. These slides were subjected for deparaffinization and rehydration. Endogenous peroxidase activity was quenched by $3 \% \mathrm{H}_{2} \mathrm{O}_{2}$ for $20 \mathrm{~min}$ at room temperature. For antigen retrieval, the tissue sections were microwaved in citrate buffer ( $\mathrm{pH} \mathrm{6.0)} \mathrm{for} 30 \mathrm{~min}$. The tissue sections were incubated with $3 \%$ skimmed milk in PBS, $\mathrm{pH} 7.4$ at room temperature. The tissue sections were incubated with primary antibodies at following dilutions anti-amphiphysin (dilution 1:100, catalog \# ab52646), anti-neurofascin (dilution1:250, catalog \# ab31457), antiferritin light chain (dilution 1:500, catalog \# ab69090) which were purchased from Abcam (Cambridge UK). 


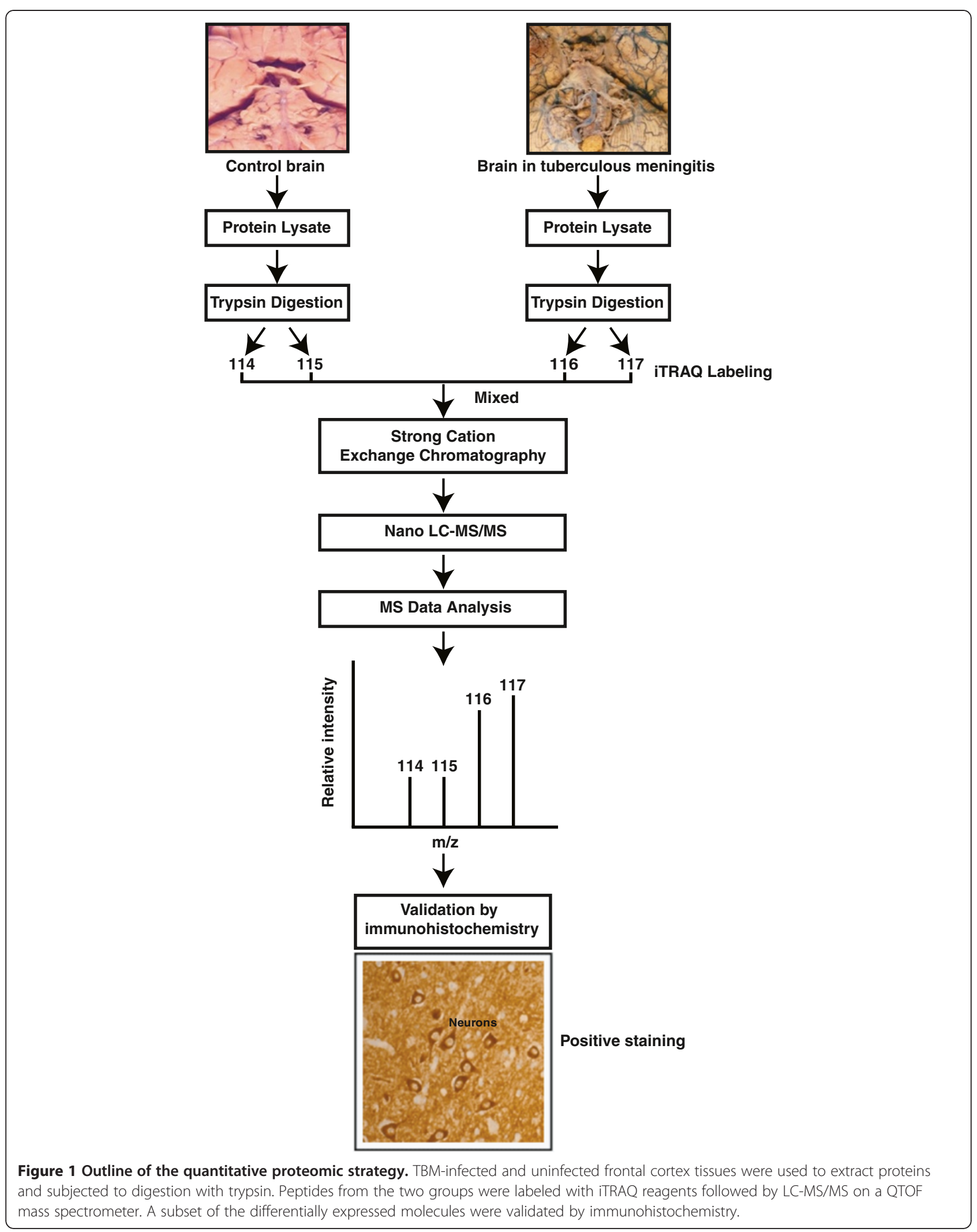


In parallel with test slides, negative and positive controls were also subjected for overnight incubation at room temperature, followed by incubation with prediluted secondary antibody conjugated with poly HRP (catalog \# K4011) from Dako. The reaction was visualized with chromogen substrate DAB/H2O2 (Dako catalog \# K4007) as per manufacturer's instructions. The sections were counterstained with hematoxylin.

\section{Results and discussion}

We used six TBM and six uninfected samples for our quantitative proteomic analysis. The overall workflow for the study is depicted in Figure 1. The tandem mass spectra were searched against human NCBI RefSeq release 40 (31,811 protein sequences) using Mascot and Sequest search engines through the Proteome Discoverer software. A total of 81,494 spectra were acquired which resulted in 5,988 peptide-spectrum matches. We identified a total of 434 proteins with 919 unique peptides. The protein and peptide data is provided in Additional file 2: Table S2 and Additional file 3: Table S3, respectively. In all, we identified 110 upregulated and 24 downregulated proteins at 1\% FDR. The distribution of cellular localization and biological processes of the differentially expressed proteins is shown in Figure 2A and B. The subcellular localization and biological processes of the differentially expressed proteins were classified based on annotations in Human Protein Reference Database (HPRD, http://hprd.org) [35]. Partial list of differentially expressed proteins are provided in Tables 1 and 2 .

\section{Proteins previously implicated in TBM and tuberculosis associated studies}

Proteins that have previously been implicated in TBM and tuberculosis associated studies included Vimentin (VIM), Peroxiredoxin 5 (PRDX5), Glial fibrillary acidic protein (GFAP), Signal-regulatory protein alpha (SIRPA) and Protein disulfide isomerase family A, member 6 (PDIA6). VIM is an intermediate filament family protein and is also the potential ligand for natural cytotoxicity triggering receptor 1 (NKp46). VIM was shown to be 2.8fold upregulated in the present study. VIM is involved in the lysis of the MTB-infected cells through NKp46 $[36,37]$. PRDX5 is a member of the peroxiredoxin family

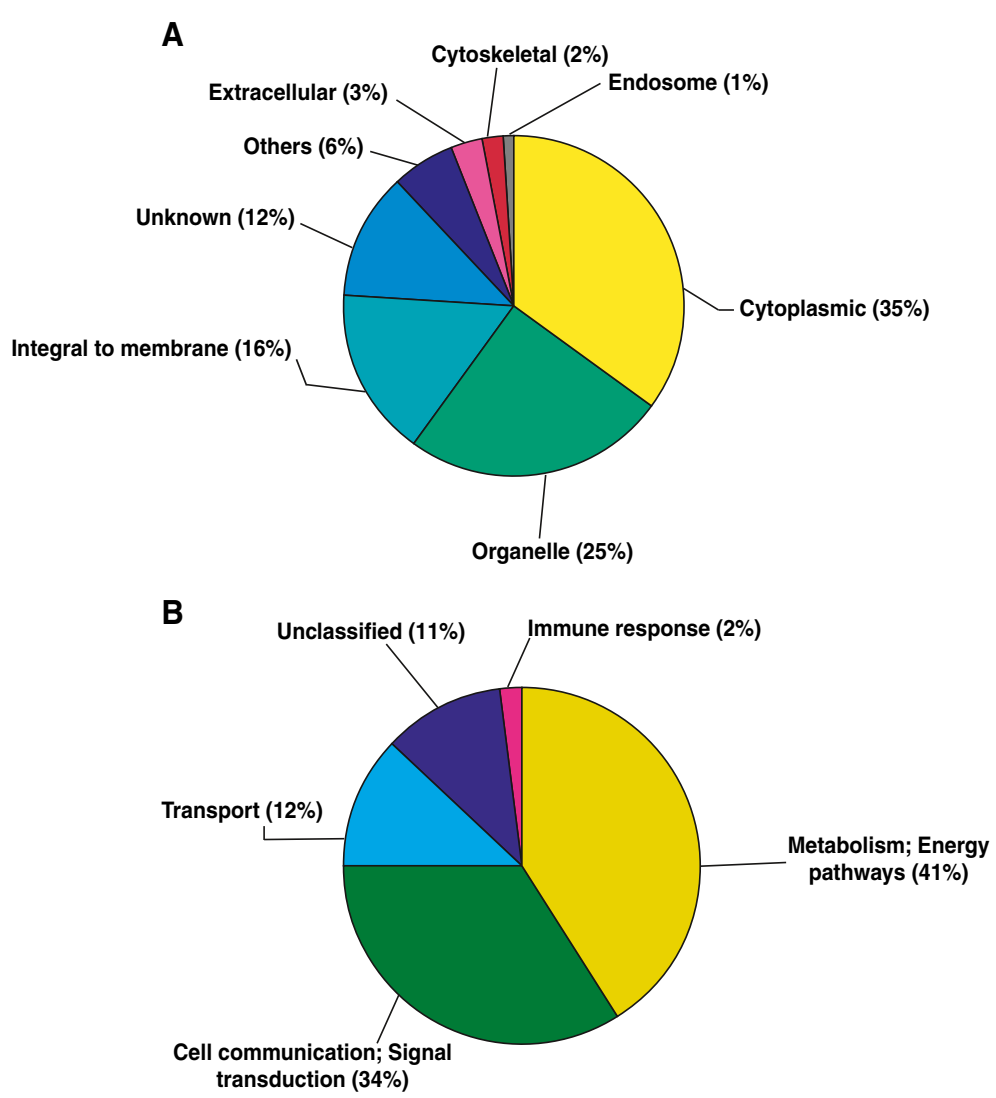

Figure 2 Subcellular localization and biological process of differentially expressed proteins. Subcellular localization (A) and biological process (B) of differential expressed proteins are shown. 
Table $1 \mathrm{~A}$ partial list of proteins overexpressed in TBM

\begin{tabular}{llll}
\hline & $\begin{array}{l}\text { Gene } \\
\text { Symbol }\end{array}$ & Protein & Description \\
\hline 1 & WARS & $\begin{array}{l}\text { Tryptophanyl-tRNA synthetase, cytoplasmic } \\
\text { isoform b }\end{array}$ & $\begin{array}{l}\text { It induced by interferon and involved in the catalyzation } \\
\text { of the aminoacylation of tRNA (trp) with tryptophan. }\end{array}$ \\
\hline 2 & SLC4A4 & $\begin{array}{l}\text { Electrogenic sodium bicarbonate } \\
\text { cotransporter 1 isoform 2 }\end{array}$ & $\begin{array}{l}\text { It plays a functional role in the regulation of bicarbonate } \\
\text { secretion and absorption and intracellular pH. }\end{array}$ \\
\hline 3 & NPM1 & Nucleophosmin isoform 3 & $\begin{array}{l}\text { It is a phosphoprotein which shuttles between the } \\
\text { nucleus and the cytoplasm. It plays a role in ARF/p53 } \\
\text { signaling pathway. }\end{array}$ \\
\hline 4 & DHX9 & ATP-dependent RNA helicase A & $\begin{array}{l}\text { It localizes to cytoplasm and nucleus. It acts as a } \\
\text { transcriptional regulator. }\end{array}$ \\
\hline 5 & HPCA & $\begin{array}{l}\text { Neuron-specific calcium-binding protein } \\
\text { hippocalcin }\end{array}$ & $\begin{array}{l}\text { It belongs to the neuron-specific calcium-binding } \\
\text { proteins family. It may play a role in the neurons of } \\
\text { the central nervous system. }\end{array}$ \\
\hline 6 & GPM6A & Neuronal membrane glycoprotein & $\begin{array}{l}\text { It is a transmembrane protein and expressed on neurons } \\
\text { in the central nervous system. }\end{array}$ \\
\hline 7 & GFAP & Glial fibrillary acidic protein isoform 2 & $\begin{array}{l}\text { It is an intermediate filament protein and a marker for } \\
\text { astrocytes. It is overexpressed in astrogliosis. }\end{array}$ \\
\hline 8 & SLC8A2 & Sodium/calcium exchanger 2 precursor & $\begin{array}{l}\text { It is a Sodium/calcium exchanger, regulates the } \\
\text { intracellular calcium concentrations. }\end{array}$ \\
\hline 9 & VIM & Vimentin & $\begin{array}{l}\text { It belongs to the intermediate filament protein family. } \\
\text { It plays a role in cell shape and integrity. }\end{array}$ \\
\hline 10 & VGF & VGF nerve growth factor inducible precursor & $\begin{array}{l}\text { It expressed in neuroendocrine cells and overexpressed } \\
\text { by nerve growth factor }\end{array}$ \\
\hline
\end{tabular}

of antioxidant enzymes. PRDX5 was found to be overexpressed in MTB (H37Rv) infected mice study [38]. In our study, it was found to be 2.2-fold overexpressed in TBM as compared to controls. PRDX5 plays an antioxidant protective role in tissues. GFAP showed 3.2-fold upregulation in TBM as compared to controls. Our finding correlated with a recent study that described a 4.7-fold overexpression of GFAP at mRNA level in TBM cases [39]. Representative MS/MS and reporter ion spectra of differentially regulated molecules are provided in Figure 3. MS/MS spectrum of GFAP is depicted in Figure 3A. SIRPA belongs to the signal regulatory family. The regulation of SIRPA expression can change the effectiveness of signaling processes. Growth factor

Table 2 A partial list of downregulated proteins in TBM

\begin{tabular}{|c|c|c|c|c|}
\hline & $\begin{array}{l}\text { Gene } \\
\text { Symbol }\end{array}$ & Protein & Description & Fold-change \\
\hline 1 & PDIA6 & $\begin{array}{l}\text { Protein disulfide-isomerase } \\
\text { A6 precursor }\end{array}$ & $\begin{array}{l}\text { It is endoplasmic reticulum (ER) resident protein and it plays } \\
\text { a role in folding of disulfide-bonded proteins }\end{array}$ & 2.0 \\
\hline 2 & KPNA4 & Importin subunit alpha-4 & It is cytoplasmic protein, recognizes nuclear localization signals. & 2.0 \\
\hline 3 & PFDN5 & Prefoldin subunit 5 isoform alpha & $\begin{array}{l}\text { It belongs to the prefoldin alpha subunit family. It is a subunit of } \\
\text { the molecular chaperone complex, involved in protein folding. }\end{array}$ & 2.5 \\
\hline 4 & GARS & Glycyl-tRNA synthetase & $\begin{array}{l}\text { It belongs to the class II family of tRNA synthetases and this protein } \\
\text { plays a role in autoimmune diseases. }\end{array}$ & 3.0 \\
\hline 5 & $\mathrm{MDH1}$ & Malate dehydrogenase, cytoplasmic & $\begin{array}{l}\text { It localized to the cytoplasm and mitochondria. It involved in } \\
\text { malate-aspartate shuttle. }\end{array}$ & 3.0 \\
\hline 6 & $A K 1$ & Adenylate kinase isoenzyme 1 & $\begin{array}{l}\text { It is an enzyme involved in regulating the adenine nucleotide } \\
\text { composition in the cell and it is localized in the cytosol. }\end{array}$ & 3.0 \\
\hline 7 & LANCLI & LanC-like protein 1 & $\begin{array}{l}\text { It is a loosely associated peripheral membrane protein which } \\
\text { belongs to the LanC family of bacterial membrane-associated } \\
\text { proteins. It plays a role in antimicrobial peptide synthesis. }\end{array}$ & 5.0 \\
\hline 8 & SNCG & Gamma-synuclein & $\begin{array}{l}\text { It belongs to the member of the synuclein family of proteins } \\
\text { and it may play a role in the pathogenesis of neurodegenerative } \\
\text { diseases. }\end{array}$ & 5.0 \\
\hline 9 & $P T P L B$ & $\begin{array}{l}\text { Protein-tyrosine phosphatase-like } \\
\text { member B }\end{array}$ & $\begin{array}{l}\text { It localizes to endoplasmic reticulum (ER) and involved in the } \\
\text { dehydration of very long chain fatty acid synthesis }\end{array}$ & 7.0 \\
\hline 10 & NCDN & Neurochondrin isoform 2 & $\begin{array}{l}\text { It is a cytoplasmic protein and may play a role in spatial } \\
\text { learning processes. }\end{array}$ & 7.0 \\
\hline
\end{tabular}


receptors and growth hormone receptor signaling is suppressed by the upregulation of SIRPA [40-43]. SIRPA regulates the NFkB activity that renders the cells resistant to TNF mediated apoptosis [44]. A recent study reported SIRPA to be 2-fold upregulated at the mRNA level in TBM [39]. In our study, also SIRPA protein was found to be 2-fold overexpressed in TBM. Protein disulfide isomerase family A, member 6 (PDIA6) is a protein that belongs to the endoplasmic reticulum (ER) and it is involved in the folding of disulphide bonded proteins [45]. This protein was shown to be downregulated (2.6-fold) in TBM at the mRNA level [39] and confirmed to be downregulated (2.5-fold) at the protein level in our study.

In our previous study on TBM using gene expression microarray, we had identified 2,434 differentially regulated transcripts [39]. In current proteomic study, 33 out of 134 differentially regulated proteins were also identified to be differentially expressed in the microarray dataset. However, only three proteins (GFAP, SIRPA, ACTB) were found to be correlated at both mRNA and protein levels, which is likely due to low correlation frequently observed between transcriptomic and proteomic studies.

\section{Differentially expressed proteins with no previous} association with TBM

We identified a large number of differentially expressed proteins, which have not been reported earlier in the literature to be associated with TBM. These novel proteins include $\mathrm{Ca}++-$ dependent secretion activator 2 (CADPS2) which belongs to the calcium-dependent activator of secretion (CAPS) protein family, and was found 3-fold upregulated in the present study. CADPS2 protein regulates the exocytosis of synaptic and dense-core vesicles in

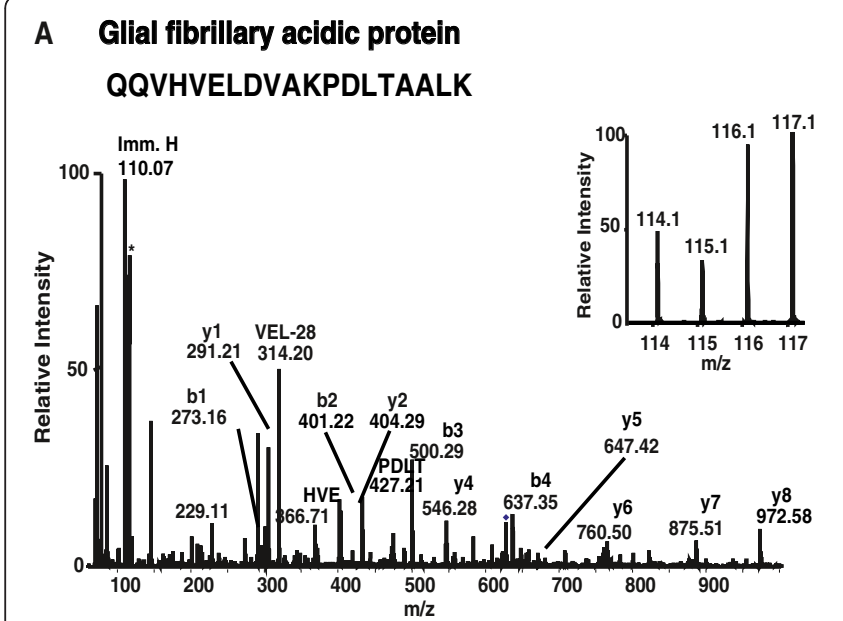

\section{Neurofascin} NLILAPGEDGR

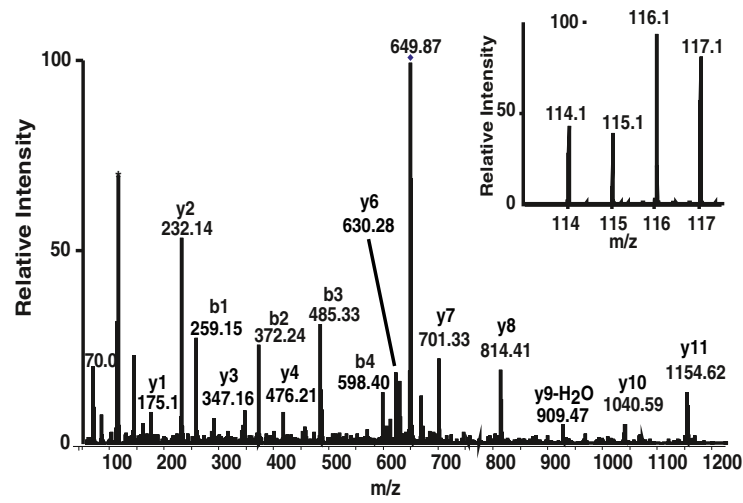

B Amphiphysin AEEPLAAVTPAVGLDLGMDTR

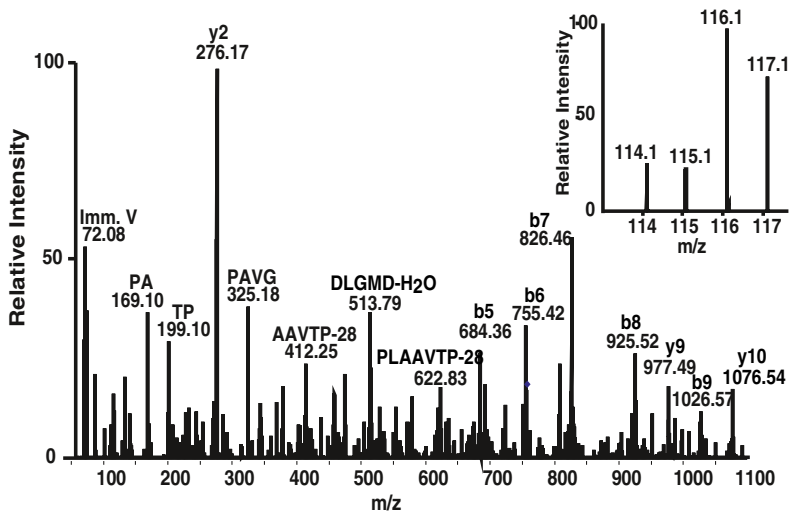

D Ferritin, light polypeptide KLNQALLDLHALGSAR

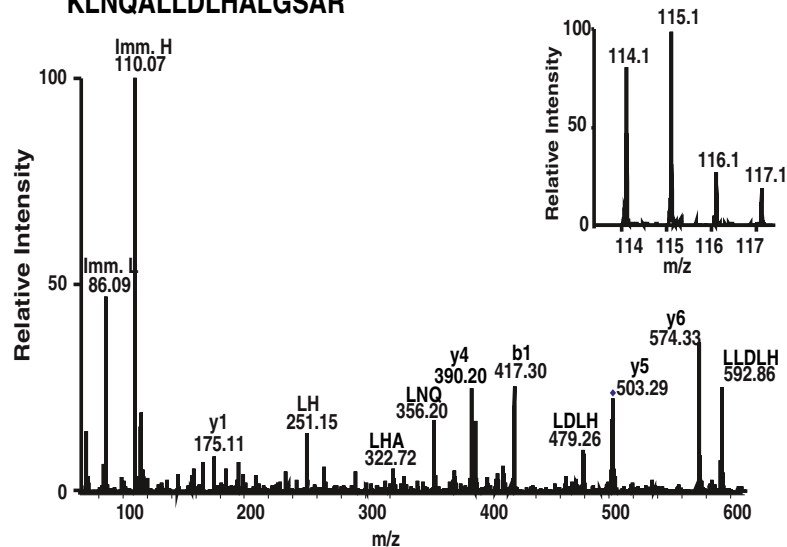

Figure 3 Representative MS and MS/MS spectra of upregulated as well as downregulated proteins. MS and MS/MS spectra of peptides from selected differentially expressed proteins identified in this study. Insets shows relative intensities of reporter ions. (A) Glial fibrilllary acid protein (GFAP); (B) Amphiphysin (AMPH); (C) Neurofascin (NFASC) (D) Ferritin, light chain (FTL). 
neurons and neuroendocrine cells [46,47]. Amphiphysin $(\mathrm{AMPH})$ (Figure $3 \mathrm{~B})$ is an adapter molecule which plays a role in synaptic vesicle endocytosis [48] and it was found to be 3.7-fold overexpressed in TBM compared to control cases. Heat shock protein $90 \mathrm{kDa}$ alpha (cytosolic), class A member 1 (HSP90AA1) is a highly conserved molecular chaperone and was found to be 2.1-fold upregulated in the present study. HSP90AA1 is a molecular chaperone, which plays a role in signal transduction, protein degradation, protein folding and is expressed under stress conditions and according to a recent report it plays a role in gene expression in mammalian cells [49]. Neurofascin (NFASC) (Figure 3C) is the L1 family immunoglobulin cell adhesion molecule, found to be 2 -fold upregulated in the current study. NFASC plays a role in organization of the axon initial segment (AIS) and nodes of Ranvier in central nervous system, neurite extension and neurite fasciculation [50-52]. Ferritin, light chain (FTL) (Figure 3D) protein is an iron storage protein which, play a role in neurodegeneration [53] and found to be 66-fold downregulated in the present study. Downregulation of FTL causes the depigmentation in metastatic melanoma cells [54] and responds during inflammation especially where oxidative stress and reactive oxygen intermediates are generated $[55,56]$.

\section{Validation of candidate biomarkers by immunohistochemical labeling}

We used immunohistochemistry (IHC) to validate a subset of differentially expressed proteins identified in iTRAQ-based study. The results from IHC validation of AMPH, NFASC and FTL from fifteen TBM cases are summarized below.

Amphiphysin (AMPH) is an adapter molecule associated with cytoplasmic surface of the synaptic vesicle, which was confirmed to be overexpressed in all 15 TBM cases tested (Figure 4). AMPH protein expression was seen diffusely distributed in synaptic fashion in the cortical ribbon in control cases (Figure 4A, B). The neurons in the grey matter showed cytoplasmic labeling with AMPH (Figure 4C). In comparison, cases of tuberculous meningitis revealed intense staining of the neuropil of the cortical ribbon reflecting upregulation of protein expression (Figure 4D, E). Several neurons showed cytoplasmic accumulation of protein within the neuronal soma (Figure 4F). Astrocytes and microglia were not labeled and white matter was devoid of labeling. Inflammatory exudates in the meninges in the cases of tuberculous meningitis also did not reveal positivity.

Neurofascin (NFASC) is an adhesion molecule, which plays an important role in cell communication and signal transduction. Overexpression of this protein was validated

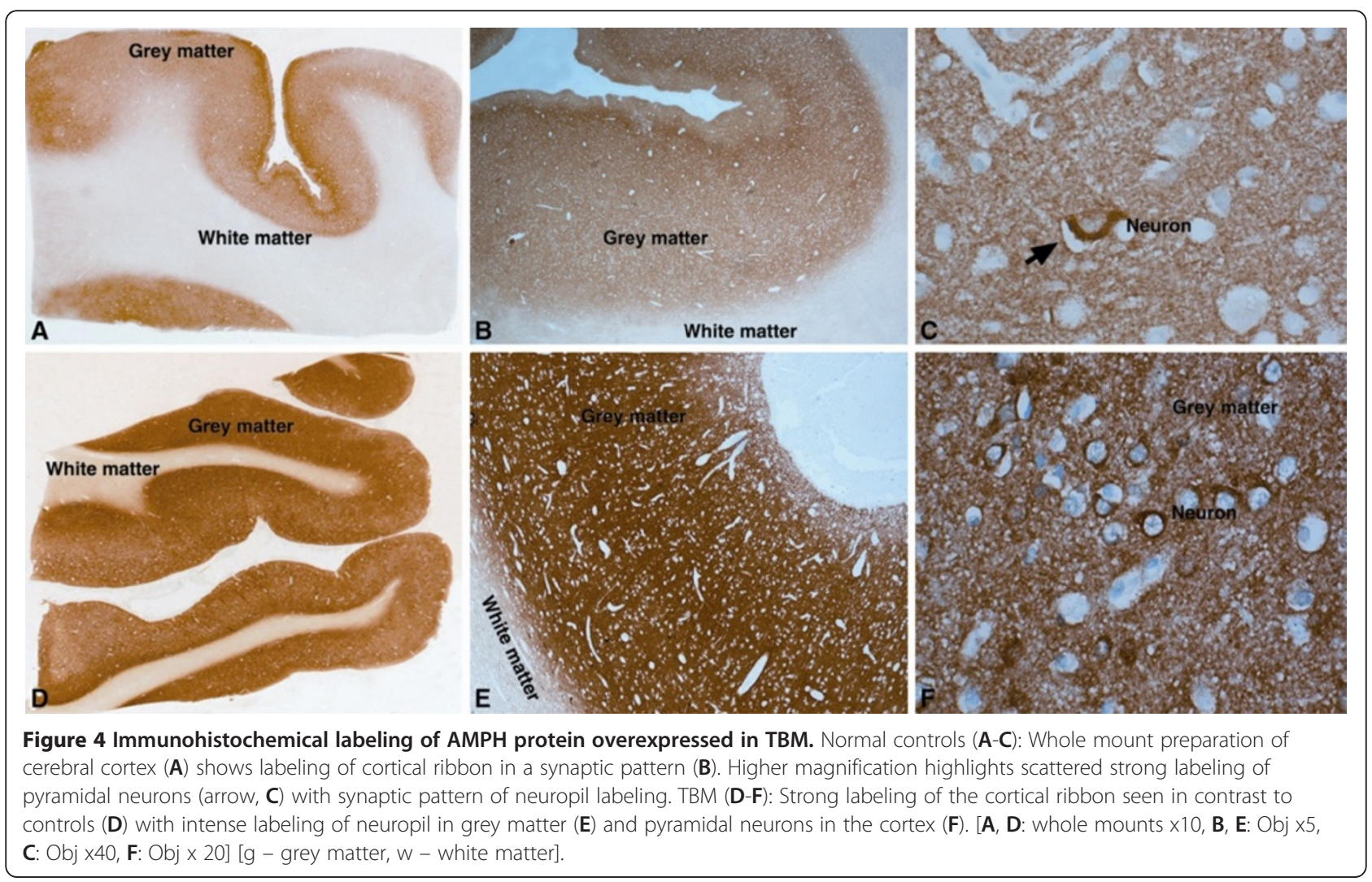




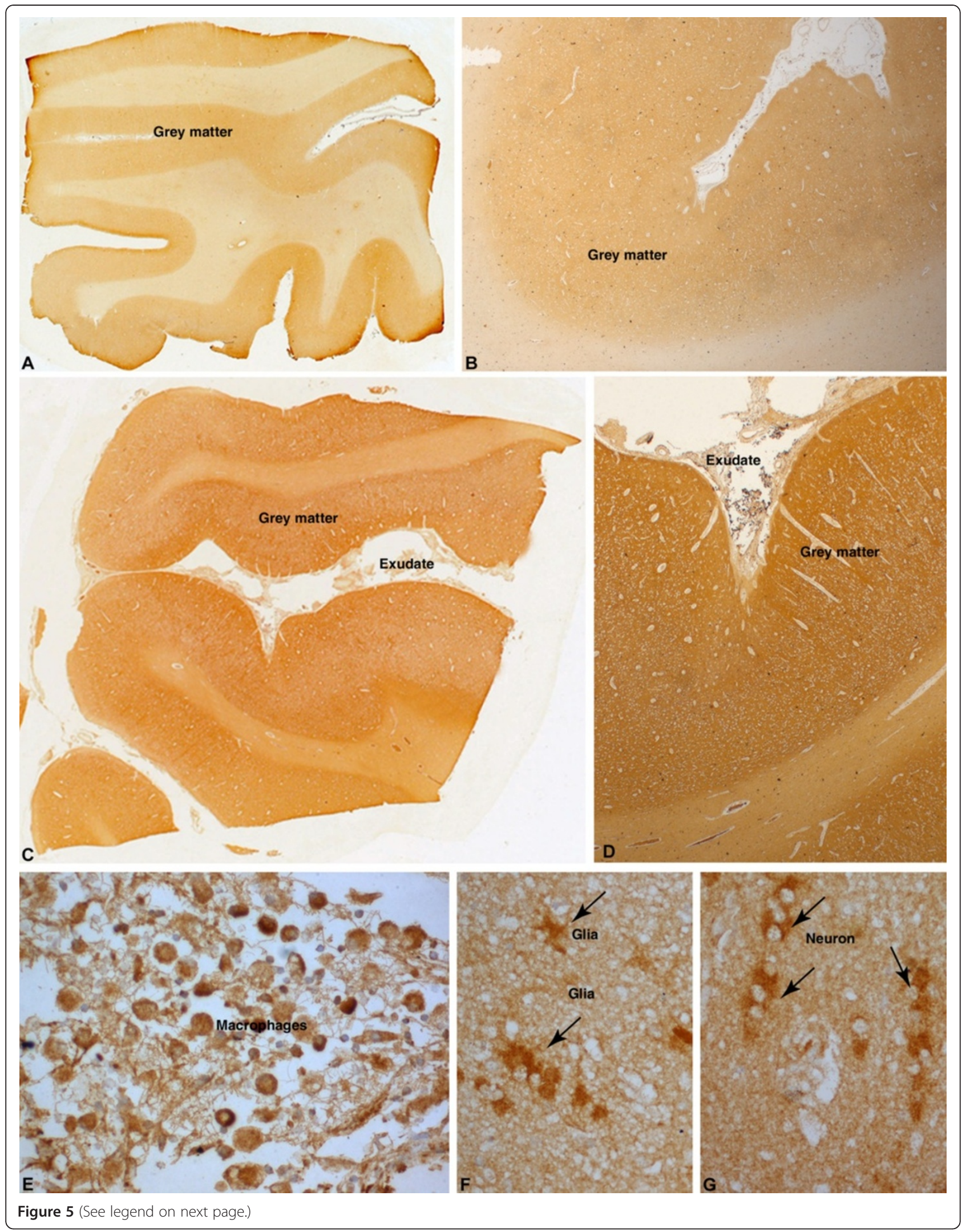


(See figure on previous page.)

Figure 5 Immunohistochemical labeling of NFASC protein overexpressed in TBM. Normal controls (A, B): Light labeling of the cortical ribbon $(\mathbf{A})$ in the frontal cortex with synaptic pattern $(\mathbf{B})$. TBM $(\mathbf{C}-\mathbf{G})$ : Whole mount preparation $(\mathbf{C})$ highlight the darker labeling of the cortical ribbon and the inflammatory exudate in the subarachnoid space. The macrophages (E) entrapped in the inflammatory exudate are strongly labeled. Glial cells (F, arrows) and linearly arranged neuronal cytoplasm (G, arrows) are strongly labeled in the grey matter. $[\mathbf{A}, \mathbf{C}: \times 10, \mathbf{B}, \mathbf{D}: \times 0 b j .5$, E-G: xObj.20].

in all 15 TBM cases. NFASC in control cases revealed positive labeling of neuropil in cortex (Figure 5A, B) with only occasional neurons showing cytoplasmic labeling in the lower cortical layers. No labeling of astrocytes or oligodendroglia was noted in control cases. In cases of tuberculous meningitis, intense labeling was seen in the neuropil of grey matter in synaptic fashion reflecting upregulated expression of protein (Figure 5C, D). Several small granule neurons expressed cytoplasmic positivity in the upper cortical layers close to the surface exudates

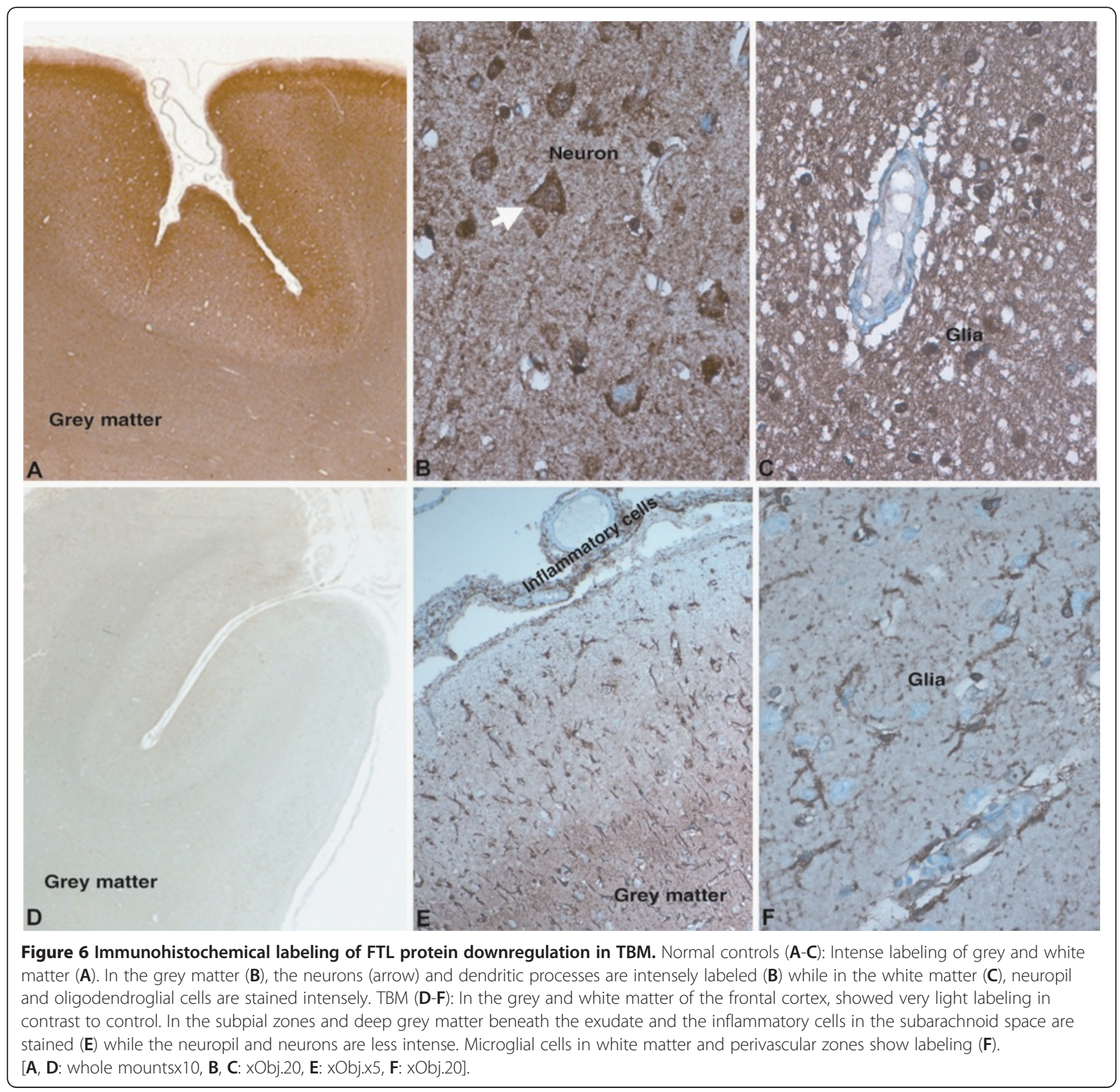


(Figure 5G). In addition, several reactive hypertrophic subpial astrocytes beneath the surface exudates expressed NFASC protein in cytoplasm extending into its branching processes (Figure 5F), in addition to macrophages in the inflammatory exudates in the subarachnoid space (Figure 5E).

Ferritin light chain (FTL) is an intracellular iron storage protein and downregulation of this protein was validated by IHC in 15 TBM cases (Figure 6). Expression of this protein was observed in control cases within the grey and white matter (Figure 6A), with grey matter showing higher intensity of expression compared to white matter. In the grey matter, neurons revealed intense labelling of the cytoplasm while dendritic processes in neuropil also revealed strong labelling (Figure 6B). In the white matter, oligodendroglial cells expressed the protein in its cytoplasm in addition to neuropil showing positivity (Figure 6C). In cases of tuberculous meningitis, marked down regulation of protein expression was seen in contrast to the normal cortex (Figure 6D). Interestingly, while neuronal expression was markedly downregulated, labelling was seen in microglial cells ensheathing neurons, as also in subpial and perivascular astrocytes seen below the inflammatory exudates in the subarachnoid spaces (Figure 6E). In the white matter, neuropil and perivascular microglia revealed protein expression in the branching ramified processes of activated miciroglia (Figure 6F).

\section{Public availability of proteomic data}

We have submitted the peptide data to Human Proteinpedia (http://www.humanproteinpedia.org) [57] and raw data files to Tranche data repository (https://proteomecommons.org/ tranche/) for easy access to the research community. The raw data is freely available in Tranche using the following hash:

xlm5a5zp5YBqpxdJpHYWlybPCdF9Bya2AH6AZRQ4 dppr593JwMsptPIJCyVnJdbpOA+YHk3eNNQnNHdDQ jeIH9c7QGsAAAAAAAFsYQ==

\section{Conclusions}

The combination of mass spectrometry and quantitative proteomics is being increasingly utilized for discovering potential biomarkers. In the current study, using an iTRAQ-based quantitative proteomic approach, we were able to identify several known and novel molecules that are differentially expressed in TBM. We validated the expression levels of three novel biomarker candidates AMPH, NFASC and FTL - by IHC on brain tissue sections from TBM cases as well as controls. These promising candidate markers warrant further evaluation in CSF from TBM patients to determine their clinical utility.

\section{Additional files}

Additional file 1: Table S1. List of TBM and control samples used in the present study.

Additional file 2: Table S2. A complete list of Proteins identified in TBM.

Additional file 3: Table S3. A complete list of peptides identified in TBM.

\section{Abbreviation}

CSF: Cerebrospinal fluid; TBM: Tuberculous meningitis; iTRAQ: Isobaric tag for relative and absolute quantitation; QTOF: Quadrupole Time-of-Flight; IHC: Immunohistochemistry; TCEP: Tris (2-carboxyethyl) phosphine; MMTS: Methyl-methanethiosulfonate; TEAB: Triethylammonium bicarbonate buffer; ACN: Acetonitrile; Poly-HRP: Polymer conjugate of horseradish peroxidase; DAB-3: 3-Diaminobenzidine; HPLC: High performance liquid chromatography; SCX: Strong cation exchange; FDR: False discovery rate.

\section{Competing interests}

The authors have declared no conflict of interest.

\section{Authors' contributions}

RC, TSKP, SKS and AP conceived the study, GSSK, YLR, PS, RC, TSKP, SKS and AP designed the experiments; GSSK, AKV, AM, SR, HCH, NAS, HP and RS, carried out the experiments; GSSK, SR, PK, RS, SRG, KW and AP analyzed the data; GSSK, SKS, and AP wrote the manuscript. All authors read and approved the final manuscript.

\section{Acknowledgments}

This study was supported by "DBT Programme Support on Neuroproteomics for Proteomic Investigation of Neurological Disorders." Nandini

Sahasrabuddhe and Harsh Pawar are recipients of Senior Research fellowship award from the Council for Scientific and Industrial Research (CSIR) of the Government of India. Santosh Renuse is a recipient of Senior Research fellowship award from the University Grants Commission (UGC) of the Government of India. Rakesh Sharma is a Research associate supported by DBT. T. S. Keshava Prasad is supported by a research grant on "Establishment of a National Database on Tuberculosis" and "Development of Infrastructure and a Computational Framework for Analysis of Proteomic Data" from DBT. Harsha Gowda is a Wellcome Trust-DBT India Alliance Early Career Fellow. Human brain tissues for the study were obtained from the Human Brain Tissue Repository, a national research facility in the Department of Neuropathology, National Institute of Mental Health and Neuro Sciences, Bangalore, India. Secretarial assistance of Mrs. Manjula Madan is acknowledged.

\section{Author details}

${ }^{1}$ Institute of Bioinformatics, International Technology Park, Bangalore 560066, India. ${ }^{2}$ Department of Biotechnology, Kuvempu University, Shimoga 577451, India. ${ }^{3}$ McKusick-Nathans Institute of Genetic Medicine, Johns Hopkins University, 733 N. Broadway, BRB 527, Baltimore, MD 21205, USA. ${ }^{4}$ Departments of Biological Chemistry, Johns Hopkins University School of Medicine, Baltimore, MD 21205, USA. ${ }^{5}$ Department of Neuropathology, National Institute of Mental Health and Neurosciences, Bangalore 560029, India. ${ }^{6}$ Amrita School of Biotechnology, Amrita Vishwa Vidyapeetham, Kollam 690525, India. ${ }^{7}$ Manipal University, Madhav Nagar, Manipal 576104, India. ${ }^{8}$ Rajiv Gandhi University of Health Sciences, Bangalore 560041, India. ${ }^{9}$ Department of Neurochemistry, National Institute of Mental Health and Neurosciences, Bangalore 560029, India. ${ }^{10}$ Agilent Technologies India Pvt. Ltd, Bangalore 560048, India. ${ }^{11}$ Agilent Technologies, Santa Clara, CA, USA. ${ }^{12}$ Department of Neurology, National Institute of Mental Health and Neurosciences, Bangalore 560029, India. ${ }^{13}$ Centre of Excellence in Bioinformatics, School of Life Sciences, Pondicherry University, Pondicherry 605014, India. ${ }^{14}$ Pathology Johns Hopkins University School of Medicine, Baltimore, MD 21205, USA. ${ }^{15}$ Oncology, Johns Hopkins University School of Medicine, Baltimore, MD 21205, USA.

Received: 10 February 2012 Accepted: 15 October 2012 Published: 30 November 2012 
References

1. World Health Organization, Geneva, Switzerland: The International Journal of Tuberculosis and Lung Disease 2006, 10:1091-1097.

2. Fanning A: Tuberculosis: 6. Extrapulmonary disease. CMAJ 1999, 160:1597-1603.

3. Garg RK: Tuberculosis of the central nervous system. Postgrad Med J 1999, 75(881):133-40.

4. Hosoglu S, Geyik MF, Balik I, et al: Predictors of outcome in patients with tuberculous meningitis. Int J Tuberc Lung Dis 2002, 6(1):64-70.

5. Thwaites GE, Nguyen DB, Nguyen HD, et al: Dexamethasone for the treatment of tuberculous meningitis in adolescents and adults. $N$ Engl $J$ Med 2004, 351(17):1741-51.

6. Berenguer J, Moreno S, Laguna F, et al: Tuberculous meningitis in patients infected with the human immunodeficiency virus. N Engl J Med 1992, 326(10):668-72.

7. Azuaje C, Fernandez Hidalgo N, Almirante B, et al: Tuberculous meningitis: a comparative study in relation to concurrent human immunodeficiency virus infection. Enferm Infecc Microbiol Clin 2006, 24(4):245-250.

8. Thwaites G, Chau TT, Mai NT, Drobniewski F, McAdam K, Farrar J: Tuberculous meningitis. J Neurol Neurosurg Psychiatry 2000 68(3):289-99.

9. Dinnes J, Deeks J, Kunst $\mathrm{H}$, et al: A systematic review of rapid diagnostic tests for the detection of tuberculosis infection. Health Technol Assess 2007, 11(3):1-196.

10. Eintracht S, Silber E, Sonnenberg P, Koornhof HJ, Saffer D: Analysis of adenosine deaminase isoenzyme-2 (ADA(2)) in cerebrospinal fluid in the diagnosis of tuberculosis meningitis. J Neurol Neurosurg Psychiatry 2000 69(1):137-8.

11. Donald PR, Malan C, van der Walt A, Schoeman JF: The simultaneous determination of cerebrospinal fluid and plasma adenosine deaminase activity as a diagnostic aid in tuberculous meningitis. S Afr Med J 1986, 69(8):505-7

12. Mishra OP, Loiwal V, Ali Z, Nath G, Chandra L: Cerebrospinal fluid adenosine deaminase activity for the diagnosis of tuberculous meningitis in children. J Trop Pediatr 1996, 42(3):129-32.

13. Kashyap RS, Kainthla RP, Mudaliar AV, Purohit HJ, Taori GM, Daginawala HF: Cerebrospinal fluid adenosine deaminase activity: a complimentary too in the early diagnosis of tuberculous meningitis. Cerebrospinal Fluid Res. 2006, 3:5.

14. Nishida $\mathrm{Y}$, Komachi $\mathrm{H}$, Mizusawa $\mathrm{H}$ : A case of Listeria meningitis associated with increased adenosine deaminase in cerebrospinal fluid. Diagn Microbiol Infect Dis 2007, 57(4):435-7.

15. Mudaliar AV, Kashyap RS, Purohit HJ, Taori GM, Daginawala HF: Detection of $65 \mathrm{kD}$ heat shock protein in cerebrospinal fluid of tuberculous meningitis patients. BMC Neurol 2006, 6:34.

16. Donald PR, Malan C: Cerebrospinal fluid lactate and lactate dehydrogenase levels as diagnostic aids in tuberculous meningitis. S Afr Med J 1985, 67(1):19-20.

17. Molavi A, LeFrock JL: Tuberculous meningitis. Med Clin North Am 1985, 69(2):315-31.

18. Wilder-Smith A, Wilder-Smith E: Tuberculous meningitis and corticosteroids: a review. Neurol J Southeast Asia 1998, 3:57-60.

19. Lorber J: The results of treatment of 549 cases of tuberculous meningitis. Am Rev Tuberc 1954, 69(1):13-25.

20. Verdon $\mathrm{R}$, Chevret $\mathrm{S}$, Laissy JP, Wolff M: Tuberculous meningitis in adults: review of 48 cases. Clin Infect Dis 1996, 22(6):982-8.

21. Chaerkady R, Pandey A: Applications of proteomics to lab diagnosis. Annu Rev Pathol 2008, 3:485-98.

22. Han X, Aslanian A, Yates JR 3rd: Mass spectrometry for proteomics. Curr Opin Chem Biol 2008, 12(5):483-90.

23. Ackermann $\mathrm{BL}$, Hale JE, Duffin $\mathrm{KL}$ : The role of mass spectrometry in biomarker discovery and measurement. Curr Drug Metab 2006, 7(5):525-39.

24. Chaerkady R, Pandey A: Quantitative proteomics for identification of cancer biomarkers. Proteomics Clin Appl 2007, 1(9):1080-9.

25. Shiio Y, Aebersold R: Quantitative proteome analysis using isotope-coded affinity tags and mass spectrometry. Nat Protoc 2006, 1(1):139-45.

26. Chaerkady $\mathrm{R}$, Harsha HC, Nalli A, et al: A quantitative proteomic approach for identification of potential biomarkers in hepatocellular carcinoma. J Proteome Res 2008, 7(10):4289-98.
27. Choe L, D'Ascenzo M, Relkin NR, et al: 8-plex quantitation of changes in cerebrospinal fluid protein expression in subjects undergoing intravenous immunoglobulin treatment for Alzheimer's disease. Proteomics 2007, 7(20):3651-60.

28. Martin B, Brenneman R, Becker KG, Gucek M, Cole RN, Maudsley S: iTRAQ analysis of complex proteome alterations in 3xTgAD Alzheimer's mice: understanding the interface between physiology and disease. PLOS One 2008, 3(7):e2750

29. Pawar H, Kashyap MK, Sahasrabuddhe NA, et al: Quantitative tissue proteomics of esophageal squamous cell carcinoma for novel biomarker discovery. Cancer Biol Ther 2011, 12(6):510-22.

30. Prasad TSK, Keerthikumar S, et al: Comparative proteomic analysis of Candida albicans and Candida glabrata. Clinical Proteomics 2010, 6:163-173.

31. Ross PL, Huang YN, Marchese JN, et al: Multiplexed protein quantitation in Saccharomyces cerevisiae using amine-reactive isobaric tagging reagents. Mol Cell Proteomics 2004, 3(12):1154-69.

32. Venugopal A, Chaerkady R, Pandey A: Application of mass spectrometrybased proteomics for biomarker discovery in neurological disorders. Ann Indian Acad Neurol. 2009, 12(1):3-11.

33. Yang W, Woltjer RL, Sokal I, et al: Quantitative proteomics identifies surfactant-resistant alpha-synuclein in cerebral cortex of Parkinsonismdementia complex of Guam but not Alzheimer's disease or progressive supranuclear palsy. Am J Pathol 2007, 171(3):993-1002.

34. Zieske LR: A perspective on the use of iTRAQ reagent technology for protein complex and profiling studies. J Exp Bot 2006, 57(7):1501-8.

35. Goel R, Muthusamy B, Pandey A, Prasad TS: Human protein reference database and human proteinpedia as discovery resources for molecular biotechnology. Mol Biotechnol 2011, 48(1):87-95.

36. Garg A, Barnes PF, Porgador A, et al: Vimentin expressed on Mycobacterium tuberculosis-infected human monocytes is involved in binding to the NKp46 receptor. J Immunol 2006, 177(9):6192-8.

37. Thuong NT, Dunstan SJ, Chau TT, et al: Identification of tuberculosis susceptibility genes with human macrophage gene expression profiles. PLoS Pathog 2008, 4(12):e1000229.

38. Beisiegel M, Mollenkopf HJ, Hahnke K, et al: Combination of host susceptibility and Mycobacterium tuberculosis virulence define gene expression profile in the host. Eur J Immunol 2009, 39(12):3369-84.

39. Kumar GSS, Venugopal AK, Selvan LDN, Marimuthu A, Keerthikumar S, Pathare S, Dikshit JB, Tata P, Hariharan R, Prasad TSK, Harsha HC, Ramachandra YL, Mahadevan A, Chaerkady R, Shankar SK, Pandey A: Gene expression profiling of tuberculous meningitis. J Proteomics Bioinformatics 2011, 4(5):98-105.

40. Wu Cl, Chen Z, Ullrich A, Greene MI, O'Rourke DM: Inhibition of EGFRmediated phosphoinositide-3-OH kinase ( $\mathrm{PI} 3-\mathrm{K})$ signaling and glioblastoma phenotype by signal-regulatory proteins (SIRPs). Oncogene 2000, 19(35):3999-4010.

41. Stofega MR, Argetsinger LS, Wang H, Ullrich A, Carter-Su C: Negative regulation of growth hormone receptor/JAK2 signaling by signal regulatory protein alpha. J Biol Chem 2000, 275(36):28222-9.

42. Kharitonenkov A, Chen Z, Sures I, Wang H, Schilling J, Ullrich A: A family of proteins that inhibit signalling through tyrosine kinase receptors. Nature 1997, 386(6621):181-6.

43. Neznanov N, Neznanova L, Kondratov RV, O'Rourke DM, Ullrich A, Gudkov $\mathrm{AV}$ : The ability of protein tyrosine phosphatase SHP-1 to suppress NFkappaB can be inhibited by dominant negative mutant of SIRPalpha. DNA Cell Biol 2004, 23(3):175-82.

44. Neznanov N, Neznanova L, Kondratov RV, et al: Dominant negative form of signal-regulatory protein-alpha (SIRPalpha/SHPS-1) inhibits tumor necrosis factor-mediated apoptosis by activation of NF-kappa B. J Biol Chem 2003, 278(6):3809-15.

45. Hayano T, Kikuchi M: Cloning and sequencing of the cDNA encoding human P5. Gene 1995, 164(2):377-8.

46. Berwin B, Floor E, Martin TF: CAPS (mammalian UNC-31) protein localizes to membranes involved in dense-core vesicle exocytosis. Neuron 1998 21(1):137-45.

47. Renden R, Berwin B, Davis W, et al: Drosophila CAPS is an essential gene that regulates dense-core vesicle release and synaptic vesicle fusion. Neuron 2001, 31(3):421-37.

48. Wigge $P$, Kohler $K$, Vallis $Y$, et al: Amphiphysin heterodimers: potential role 
in clathrin-mediated endocytosis. Mol Biol Cell 1997, 8(10):2003-15.

49. Vozzolo L, Loh B, Gane PJ, et al: Gyrase B inhibitor impairs HIV-1 replication by targeting $\mathrm{Hsp} 90$ and the capsid protein. J Biol Chem 2010 285(50):39314-28

50. Zonta B, Tait S, Melrose S, et al: Glial and neuronal isoforms of Neurofascin have distinct roles in the assembly of nodes of Ranvier in the central nervous system. J Cell Biol 2008, 181(7):1169-77.

51. Zonta B, Desmazieres A, Rinaldi A, et al: A critical role for Neurofascin in regulating action potential initiation through maintenance of the axon initial segment. Neuron 2011, 69(5):945-56.

52. Koticha D, Babiarz J, Kane-Goldsmith N, Jacob J, Raju K, Grumet M: Cell adhesion and neurite outgrowth are promoted by neurofascin NF155 and inhibited by NF186. Mol Cell Neurosci 2005, 30(1):137-48.

53. Friedman A, Arosio P, Finazzi D, Koziorowski D, Galazka-Friedman J: Ferritin as an important player in neurodegeneration. Parkinsonism Relat Disord 2011, (6):423-430.

54. Maresca V, Flori E, Cardinali G, et al: Ferritin light chain down-modulation generates depigmentation in human metastatic melanoma cells by influencing tyrosinase maturation. J Cell Physiol 2006, 206(3):843-8.

55. Roeser $\mathrm{H}$, Jacobs A, Worwood M: In Iron metabolism in biochemistry and medicine. Volume 2. Edited by Jacobs A, Worwood M.; 1980:605-640

56. Kwak EL, Larochelle DA, Beaumont C, Torti SV, Torti FM: J Biol Chem 1995, 270:15285-15293.

57. Kandasamy K, Keerthikumar S, Goel R, et al: Human Proteinpedia: a unified discovery resource for proteomics research. Nucleic Acids Res 2009, 37(Database issue):D773-781.

doi:10.1186/1559-0275-9-12

Cite this article as: Kumar et al: Quantitative proteomics for identifying biomarkers for tuberculous meningitis. Clinical Proteomics 2012 9:12.

\section{Submit your next manuscript to BioMed Central and take full advantage of:}

- Convenient online submission

- Thorough peer review

- No space constraints or color figure charges

- Immediate publication on acceptance

- Inclusion in PubMed, CAS, Scopus and Google Scholar

- Research which is freely available for redistribution 